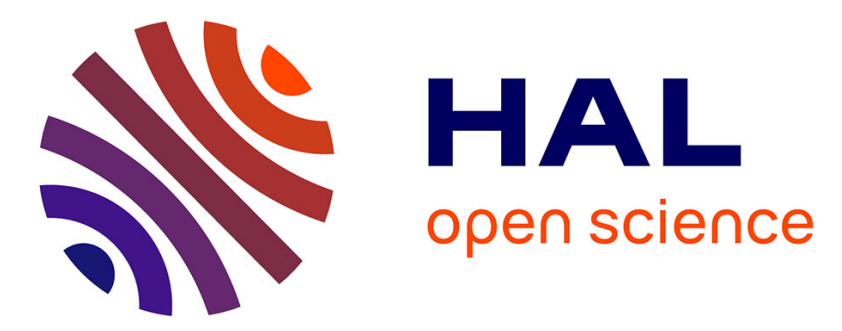

\title{
Thermal decomposition of zinc carbonate hydroxide
}

\author{
Ndue Kanari, Devabrata Mishra, I. Gaballah, Bernard Dupré
}

\section{To cite this version:}

Ndue Kanari, Devabrata Mishra, I. Gaballah, Bernard Dupré. Thermal decomposition of zinc carbonate hydroxide. Thermochimica Acta, 2004, 410, pp. 93-100. 10.1016/S0040-6031(03)00396-4 . hal-01507382

\section{HAL Id: hal-01507382 \\ https://hal.univ-lorraine.fr/hal-01507382}

Submitted on 4 May 2017

HAL is a multi-disciplinary open access archive for the deposit and dissemination of scientific research documents, whether they are published or not. The documents may come from teaching and research institutions in France or abroad, or from public or private research centers.
L'archive ouverte pluridisciplinaire HAL, est destinée au dépôt et à la diffusion de documents scientifiques de niveau recherche, publiés ou non, émanant des établissements d'enseignement et de recherche français ou étrangers, des laboratoires publics ou privés. 


\title{
Revised Version
}

\section{Thermal Decomposition of Zinc Carbonate Hydroxide}

\author{
N. Kanari ${ }^{25}$, D. Mishra, I. Gaballah, and B. Dupré* \\ Mineral Processing and Environmental Engineering Team, \\ LEM $^{\mathrm{a}}, \mathrm{CNRS}^{\mathrm{b}} \mathrm{UMR}^{7569}, \mathrm{ENSG}^{\mathrm{c}}, \mathrm{INPL}^{\mathrm{d}}$, BP 40, 54501 Vandœuvre, France \\ * Laboratoire de Chimie du Solide Minérale, Associated to CNRS UMR 7555 \\ Université Henri Poincaré, Bvd des Aiguillettes, BP 239, 54506 Vandœuvre, France
}

: Corresponding author, E-mail : ndue.kanari@ensg.inpl-nancy.fr

This study is devoted to the thermal decomposition of two zinc carbonate hydroxide samples up to $400{ }^{\circ} \mathrm{C}$. Thermogravimetric analysis (TGA), boat experiments and differential scanning calorimetry (DSC) measurements were used to follow the decomposition reactions. The initial samples and the solid decomposition products were analyzed by scanning electron microscopy (SEM), X-ray diffraction (XRD), Fourier transform infra-red (FTIR) and laser particle size analyzer.

Results showed that zinc carbonate hydroxide decomposition started at about $150{ }^{\circ} \mathrm{C}$ and the rate of decomposition became significant at temperatures higher than $200{ }^{\circ} \mathrm{C}$. The apparent activation energies ' $\mathrm{E}_{\mathrm{a}}$ ' in the temperature range $150-240{ }^{\circ} \mathrm{C}$ for these two samples 132 and $153 \mathrm{~kJ} / \mathrm{mol}$. The XRD analyses of the intermediately decomposed samples and the DSC results up to $400{ }^{\circ} \mathrm{C}$ suggested a single step decomposition of zinc carbonate hydroxide to zinc oxide with not much change in their overall morphologies.

Key Words: Zinc carbonate hydroxide, thermal decomposition, zinc oxide

\footnotetext{
a. Laboratoire Environnement et Minéralurgie, rue du Doyen M. Roubault, BP 40, 54501 Vandœuvre Cedex, France.

b. Centre National de la Recherche Scientifique, 3 rue MichelAnge, 75794 Paris Cedex, France.

c. École Nationale Supérieure de Géologie, rue du Doyen M. Roubault, BP 40, 54501 Vandœuvre Cedex, France.

d. Institut National Polytechnique de Lorraine, 2 rue de la Forêt de Haye, 54501 Vandœuvre Cedex, France.
} 


\section{Introduction}

Preparation of different grades of zinc oxide has been the subject of many recent researches [1-3]. This is due to the diversified applications of $\mathrm{ZnO}$ which include manufacture of varistors, used as protection elements in electric and electronic appliances, as a polymer dispersant and heat absorbant in tyre industry, in cosmetics as UV light absorber and in paints and pigment industry as a color hue [4-6]. This compound is commercially produced by zinc vaporization and its subsequent oxidation (French and American Processes), but majority of lab scale R \& D activities are focused on precursor calcination methods. Zinc oxides from the decomposition of hydroxy-carbonates are energetically favorable due to their lower decomposition temperature in comparison to other zinc oxide precursors (such as hydroxides, carbonates, acetates, oxalates, etc.). Further, it is well known that the composition and the properties of zinc carbonate hydroxides are largely dependent on the precipitation conditions, variation of which led to different grades of $\mathrm{ZnO}[7,8]$.

Thermal decomposition is an essential step for preparation of $\mathrm{ZnO}$ from the precipitated precursors. The mechanism and kinetics of thermal decomposition of zinc carbonates (anhydrous, hydrated and hydroxy or basic carbonates) were reported by several authors [9-14]. Recently, thermal decomposition kinetics of anhydrous $\mathrm{ZnCO}_{3}$ was studied by Gotor et al. [9], in the temperature range of $330-452{ }^{\circ} \mathrm{C}$. They suggested two different 'nucleation and growth' mechanisms at different temperature ranges by comparing the results of isothermal TG and constant rate thermal analysis (CRTA). The estimated apparent activation energy ' $E_{a}$ ' was found to be $224 \mathrm{~kJ} / \mathrm{mol}$ and $140 \mathrm{~kJ} / \mathrm{mol}$ in the temperature ranges of $347-402{ }^{\circ} \mathrm{C}$ and $402-452{ }^{\circ} \mathrm{C}$, respectively. Heide and Knorr [10] reported a value of ' $\mathrm{E}_{\mathrm{a}}$ ' equal to $113 \mathrm{~kJ} / \mathrm{mol}$ for the decomposition of smithsonite $\left(\mathrm{ZnCO}_{3}\right)$ in the temperature range of $269-434{ }^{\circ} \mathrm{C}$. Galvez and Arana [11] had studied the kinetics of non-isothermal decomposition of $\mathrm{ZnCO}_{3}$ by constant heating rate TGA. They reported a value of ' $\mathrm{E}_{\mathrm{a}}$ ' $=88.6 \mathrm{~kJ} / \mathrm{mol}$ within the temperature range of $175-462{ }^{\circ} \mathrm{C}$. Similarly, one of the earlier studies on the thermal decomposition of hydrated zinc carbonate $\left(\mathrm{ZnCO}_{3} \cdot 2 \mathrm{ZnO} \cdot 2 \mathrm{H}_{2} \mathrm{O}\right)$ was performed by Dollimore et al. [12]. They suggested that the decomposition proceeds through two thermally overlapping stages with a constant reaction interface area. On the basis of isothermal TG between 200 to $260{ }^{\circ} \mathrm{C}$ they reported an activation energy $94 \pm 9 \mathrm{~kJ} / \mathrm{mol}$. The non-isothermal decomposition of a PROLABO zinc carbonate sample was reported by Gadalla [13] by using TG and DTA under different heating rates. He obtained an average activation energy of $97 \mathrm{~kJ} / \mathrm{mol}$. Recently, only one report by Jianxun et al. [14] on the decomposition kinetics of precipitated $\mathrm{Zn}_{4} \mathrm{CO}_{3}(\mathrm{OH})_{6} \cdot \mathrm{H}_{2} \mathrm{O}$ is available. Based on the DTA results under different heating rates $\left(4-20^{\circ} \mathrm{C} / \mathrm{min}\right)$ they suggested a single step decomposition process with an activation energy of $113 \mathrm{~kJ} / \mathrm{mol}$. The large discrepancy in the value of the activation energies reported by the above authors could be attributed to different sample origins, methods employed for kinetic studies and the poor characterization of the studied samples in most of the cases. 
This paper is focused on the thermal decomposition behavior of two well- characterized zinc carbonate hydroxide samples. This work was carried out in the frame of an integrated research program for clean and cost effective treatment of electric arc furnace dust (EAFD). The objective of this research is to produce commercial grade $\mathrm{ZnO}$ from EAFD. Zinc carbonate hydroxide was precipitated by $\mathrm{Na}_{2} \mathrm{CO}_{3}$ under ambient conditions from the purified dust leach liquor and subsequently thermally treated. The thermal decomposition behavior of this zinc carbonate hydroxide sample was compared with a chemically pure reference PROLABO sample.

\section{Materials and Experimental Procedure}

Two zinc carbonate hydroxide samples were used in this study. One chemical grade supplied by PROLABO and designated as reference sample 'RFS'. The other one was obtained by purification / precipitation of $\mathrm{ZnCl}_{2}$ solution from leaching of electric arc furnace dust. This sample is designated as the industrial sample 'INS'. The characterization of these samples were done by scanning electron microscopy (SEM) equipped with an energy dispersive X-ray unit (EDS), X-ray diffraction (XRD), Fourier transform infra-red (FTIR) in the range of 700-4000 $\mathrm{cm}^{-1}$ and chemical analyses.

Thermogravimetric decomposition tests were performed using $60 \mathrm{mg}$ of sample and a SETARAM microbalance having a sensitivity of $10 \mu \mathrm{g}$. All the experiments were carried out with constant flow of inert gases $\left(\mathrm{N}_{2}\right.$, Ar, dried by $\mathrm{P}_{2} \mathrm{O}_{5}$ columns) inside the reactor,. Experimental tests were carried out under non - isothermal and isothermal conditions. The maximum temperature of the isothermal treatment was chosen so that the weight loss during non-isothermal period did not exceed $7 \%$ that is about $28 \%$ of the decomposition reaction.

Boat experiments in isothermal conditions were performed using about 2 grams of samples. The final decomposed products obtained at several temperatures were subjected to SEM and XRD analyses as well as particle size measurements.

\section{Results and Discussion}

\subsection{Characterizations of Zinc Carbonate hydroxides :}

The XRD patterns of the two zinc carbonate hydroxide samples are shown in Figure 1. In both the samples all the major peak positions correspond to either $\mathrm{Zn}_{5}\left(\mathrm{CO}_{3}\right)_{2}(\mathrm{OH})_{6}$ (hydrozincite) or $\mathrm{Zn}_{4}\left(\mathrm{CO}_{3}\right)(\mathrm{OH})_{6} \cdot \mathrm{H}_{2} \mathrm{O}$ phase [15]. From this figure it seems that the sample obtained from EAFD (INS) is less crystalline than the PROLABO (RFS) sample. Laser particle size analysis suggest two 
size distributions for PROLABO sample with a $\mathrm{d}_{50}$ of $12.7 \mu \mathrm{m}$, while the industrial sample have a uniform size distribution with a $\mathrm{d}_{50}$ of $25.5 \mu \mathrm{m}$. Chemical and SEM-EDS (Figure 2) analysis of INS showed the presence of $\mathrm{Na}, \mathrm{Ca}$ and $\mathrm{Cl}$ as the major impurities. The total impurity percentage of INS is less than $5 \%$ with $\mathrm{Cl}$ as the major one (2\%). Chemical analysis of this sample showed a $\mathrm{Zn}$ content of about $50 \%$ in contrast to $59 \%$ in hydrozincite. The hydrozincite phase was further confirmed from the FTIR spectra (Figure 3) of the PROLABO sample. The strong and broad band centered at about $3317 \mathrm{~cm}^{-1}$ is the characteristic -OH stretching vibrations in hydrozincite [16]. These type of bands correspond to $-\mathrm{OH}$ groups co-ordinated to the metal ions indicating the absence of free / loosely bound water molecules. The other peaks in this spectrum can be assigned as: at 1517 and $1390 \mathrm{~cm}^{-1}$ ( $v_{3}$ mode of carbonate), at 1047, 954 and $890(\mathrm{sh}) \mathrm{cm}^{-1}$ (-OH liberation modes), at $835 \mathrm{~cm}^{-1}\left(v_{2}\right.$ mode of carbonate), at $737(\mathrm{sh})$ and $710 \mathrm{~cm}^{-1}\left(v_{4}\right.$ mode of carbonate) and the satellite peaks between $1750-2950 \mathrm{~cm}^{-1}$ region are due to various combination modes in hydrozincite [16].

\subsection{Non Isothermal TG Treatment :}

A series of non isothermal tests of the reference sample (RFS) and the sample obtained from EAFD processing (INS), was carried out from room temperature up to $400{ }^{\circ} \mathrm{C}$ with an heating rate of $5{ }^{\circ} \mathrm{C} / \mathrm{min}$ and steady flow of argon as carrier gas. Results are shown in Figure 4 as evolution of $\%$ weight loss (\% WL) Vs temperature. This figure also contains the calculated \% WL (25.88\%) for the decomposition of $\mathrm{Zn}_{5}\left(\mathrm{CO}_{3}\right)_{2}(\mathrm{OH})_{6}$ to $\mathrm{ZnO}$. The shape of these curves for both samples is similar. However, the INS seems to be more affected by temperature than RFS. As shown by Figure 4 , the weight loss increase slightly with temperature up to $200{ }^{\circ} \mathrm{C}$, since then, the decomposition rate becomes fast and almost full decomposition is reached at about $350{ }^{\circ} \mathrm{C}$.

The decomposition of the reference sample in nitrogen was studied using different heating rates from 1 to $10{ }^{\circ} \mathrm{C} /$ minute and the results obtained are shown in Figures 5. With increasing heating rate the decomposition temperature increased appreciably. This indicates the slow kinetics nature of the thermal decomposition reaction of zinc hydroxy-carbonate into zinc oxide.

\subsection{Isothermal TG Analysis :}

Isothermal decomposition studies on both the samples were performed in the temperature range 150 to $240{ }^{\circ} \mathrm{C}$ under flow of nitrogen. Figure 6 ( $a$ and $b$ ) shows the data obtained during the treatment of RFS in the above-mentioned conditions. They represent the evolution of $\%$ WL $V s$ time. The weight loss observed at time "zero" correspond to the decomposition of sample from room temperature $\left(20^{\circ} \mathrm{C}\right)$ up to the fixed temperature of the isothermal treatment. As shown by Figure 6 a, more than 160 hours are required to achieve $17 \% \mathrm{WL}$ of the sample at $150{ }^{\circ} \mathrm{C}$. While, 
about 1 hour is sufficient for the full decomposition at $240{ }^{\circ} \mathrm{C}$ (Figure $6 \mathrm{~b}$ ). The sigmoid shape of the obtained curves indicate a most probable nucleation and growth processes. However, suggestion of a mechanism will be of over simplification with present experimental data. Similar curves were also obtained in case of the industrial sample (Figures 7 a \& b). By comparing Figures 6 and 7 it is observed that INS takes longer time in comparison to RFS to achieve same weight loss at same temperature, indicating a slower kinetics of decomposition of the former. The slower decomposition rate of INS may be either due to their larger particle size or due to the presence of impurities notably $\mathrm{Cl}$. The Arrhenius diagram obtained with the data of Figures $6 \& 7$ are presented in Figure 8. The apparent activation energy calculated from the slopes of these straight lines are 132 \pm 5 and $153 \pm 4 \mathrm{~kJ} / \mathrm{mol}$ for RFS and INS respectively.

\subsection{Isothermal Boat Experiments and Characterization of Decomposed Products :}

Isothermal boat experiments (with about $2 \mathrm{~g}$ of samples) under air flow were carried on RFS from 200 to $275^{\circ} \mathrm{C}$. The decomposed products obtained at several temperatures were subjected for XRD, SEM, DSC, and particle size analyses. The evolution of $\%$ WL with time at four different temperatures is presented in Figure 9. The shape of the curves is almost similar to that obtained in case of vertical TG analysis. It is observed that full decomposition is achieved within 30 minutes at $275{ }^{\circ} \mathrm{C}$, whereas about $70 \%$ decomposition is achieved at $200{ }^{\circ} \mathrm{C}$ for 3 hours. This suggests the highly dependence of this decomposition reaction on temperature.

The X-ray diffraction patterns of two typical samples, one fully decomposed obtained at $250{ }^{\circ} \mathrm{C}(\mathrm{WL}=25.85 \%)$, and another intermediately decomposed sample obtained at $200{ }^{\circ} \mathrm{C}(\mathrm{WL}=$ $15.29 \%$ ) is shown in Figure 10. The XRD pattern of the fully decomposed sample shows the peaks for only $\mathrm{ZnO}$ while for the sample obtained at $200{ }^{\circ} \mathrm{C}$ shows the presence of both $\mathrm{ZnO}$ and hydrozincite phases [15]. The presence of anhydrous $\mathrm{ZnCO}_{3}$ was not detected in the latter sample. The DSC plot of RFS (Figure 11) up to $400{ }^{\circ} \mathrm{C}$ with a heating rate of 1 and $10{ }^{\circ} \mathrm{C} / \mathrm{min}$ show only one sharp endothermic peak at about 230 and $248{ }^{\circ} \mathrm{C}$ respectively. Combining both the XRD and DSC observations it can be concluded that the decomposition most probably occurs in a single step with simultaneous de-hydroxylation and de-carboxylation.

Laser particle size measurements were done on RFS and two samples obtained after decomposition of RFS at 250 and $400{ }^{\circ} \mathrm{C}$. These samples were dispersed ultrasonically in ethanol medium prior to their size measurements. The curves are shown in Figure 12. The size distribution of the initial and the $250{ }^{\circ} \mathrm{C}$ treated samples are almost same, having two distinct distributions whereas, the $400{ }^{\circ} \mathrm{C}$ treated sample shows more uniform distribution. The $\mathrm{d} 50$ of this sample is also decreased a little in comparison to the initial and $250{ }^{\circ} \mathrm{C}$ treated sample. 
SEM micrographs of the reference sample (RFS) and the sample obtained after its decomposition at $250{ }^{\circ} \mathrm{C}$ are compared in Figure 13. No noticeable change in their morphology is observed. In both the cases the particles are in a highly agglomerated state making it difficult to measure their sizes. These results are in agreement with that of Castellano and Matijevic [17] on calcination of hydrozincite to zinc oxide. This result further confirmed the iso-morphological thermal transformation of zinc carbonate hydroxides to zinc oxides.

\section{Conclusions}

From the above study, the following conclusions can be drawn on the thermal decomposition behavior of zinc carbonate hydroxide (hydrozincite):

1. Although, the thermal decomposition was started at lower temperature $\left(150^{\circ} \mathrm{C}\right)$ but the reaction rate was appreciable only above $200{ }^{\circ} \mathrm{C}$.

2. Presence of minor amounts of impurities in the sample 'INS' resulted a slower decomposition rate in comparison to the chemically pure 'RFS' sample.

3. The apparent activation energies obtained from the isothermal TG tests within the temperature range of $150-240{ }^{\circ} \mathrm{C}$ are $132 \pm 5 \mathrm{~kJ} / \mathrm{mol}$ for the reference sample and $153 \pm 4 \mathrm{~kJ} / \mathrm{mol}$ for the industrial sample.

4. XRD results of samples obtained in boat experiments at different extent of decomposition as well as the DSC analysis of RFS sample up to $400{ }^{\circ} \mathrm{C}$ suggested a most probable single step transformation of zinc carbonate hydroxides to $\mathrm{ZnO}$.

5. The morphological aspects during the decomposition was more or less unchanged. A minor decrease in the particle size was observed at relatively higher decomposition temperature $\left(400^{\circ} \mathrm{C}\right)$.

\section{Acknowledgments}

This work was performed in the frame of EU contract N ${ }^{\circ}$ G1RD-CT99-00166 thanks to the financial support of the European Union (DG-XII). 


\section{References}

[1] Sheng-Yuan Chu, Tser-Min Yan, Shen-Li Chen, J. Mater. Sci. Lett., 19 (2000), pp. 349-352.

[2] J.E. Rodriguez, A.C. Caballero, M. Ocana, P. Duran, J.F. Fernandez, Ceramic Processing Science, 83 (1999), 19.

[3] P. Sulcova, M. Trojan, J. Ther. Anal. Cal., 60 (2000), 209.

[4] H. Rensmo, K. Keis, H. Lindstrom, S. Sodergren, A. Solbrand, A. Hagfeldt, S.E. Lindquist, L.N. Wang, M. Muhammed, J. Phys. Chem., B 101 (1997), 2598.

[5] W. Preis, E. Konigsberger, H. Gamsjager, J. Soln. Chem., 29 (2000), 605.

[6] Z. Ruirong, C. Jianxun, J. Hanying, Journal of Central South University of Technology (China), 4 (1997), 13.

[7] L. Wang, M. Muhammed, J. Mater. Chem., 9 (1999), 2871.

[8] S. Music, D. Dragcevic, M. Maljkovic, S. Popovic, J. Mater. Chem. and Phys., 77 (2003). 521.

[9] F.J. Gotor, M. Macias, A. Ortega, J.M. Criado, Int. J. Chem. Kinet., 30 (1998), 647.

[10] Von K. Heide, J.G. Knorr, Chem. Erde Bd, 35 (1976), 256.

[11] J. Galvez, R. Arana, Univ. Murcia. Cienc., 38 (1979), 153.

[12] D. Dollimore, J.A. France, B.W. Krupay, R. Witehead, Thermochimica Acta, 36 (1980), 343.

[13] A.M. Gadalla, Int. J. Chem. Kinet., 16 (1984), 1471.

[14] Chen Jianxun, Zhao Ruirong, Jiang Hanying, Li Yanhong, Bao Gailing, Trans. Nonferrous Met. Soc. China, 8 (1998), 149.

[15] Joint Committee on Powder Diffraction Standards (JCPDS), International Center for Diffraction Data, Swathmore, PA, Files 14 - 0256 and 03 - 0787.

[16] D. Stoilova, V. Koleva, V. Vassileva, Spectrochimica Acta, Part A, 58 (2002), 2051.

[17] M. Castellano, E. Matijevic, Chemistry of Materials, 1 (1989), 78. 


\title{
Thermal Decomposition of Zinc Carbonate hydroxide
}

\author{
N. Kanari ${ }^{2}$, D. Mishra, I. Gaballah, and B. Dupré* \\ Mineral Processing and Environmental Engineering Team, \\ LEM $^{\mathrm{a}}, \mathrm{CNRS}^{\mathrm{b}} \mathrm{UMR}^{7569}, \mathrm{ENSG}^{\mathrm{c}}, \mathrm{INPL}^{\mathrm{d}}$, BP 40, 54501 Vandœuvre, France \\ * Laboratoire de Chimie du Solide Minérale, Associated to CNRS UMR 7555 \\ Université Henri Poincaré, Bvd des Aiguillettes, BP 239, 54506 Vandœuvre, France \\ : Corresponding author, E-mail : ndue.kanari@ensg.inpl-nancy.fr
}

\section{FIGURE CAPTIONS}

Figure 1: XRD results of zinc carbonate hydroxide samples.

Figure $2:$ SEM-EDS spectra of the zinc carbonate hydroxide samples

(a) : Reference sample,

(b) : Industrial sample.

Figure $3:$ FTIR of the reference sample.

Figure $4:$ TG non isothermal treatment of samples.

Figure 5: Treatment of RFS at different heating rates.

Figure 6 : Isothermal treatment of RFS between 150 and $240{ }^{\circ} \mathrm{C}$.

Figure 7 : Isothermal treatment of INS between 150 and $215^{\circ} \mathrm{C}$.

Figure $8:$ Arrhenius diagrams of decomposition of both samples.

Figure 9: Treatment of RFS between 200 and $275^{\circ} \mathrm{C}$ at different times.

Figure 10 : XRD result of RFS treated at 200 and $250{ }^{\circ} \mathrm{C}$.

Figure 11: DSC results of the reference sample.

Figure 12 : Evolution of the particle sizes during the treatment of RFS at 250 and $400{ }^{\circ} \mathrm{C}$.

Figure 13: SEM micrograph of the reference sample

(a) : Non treated,

(b) : Decomposed at $250{ }^{\circ} \mathrm{C}$. 


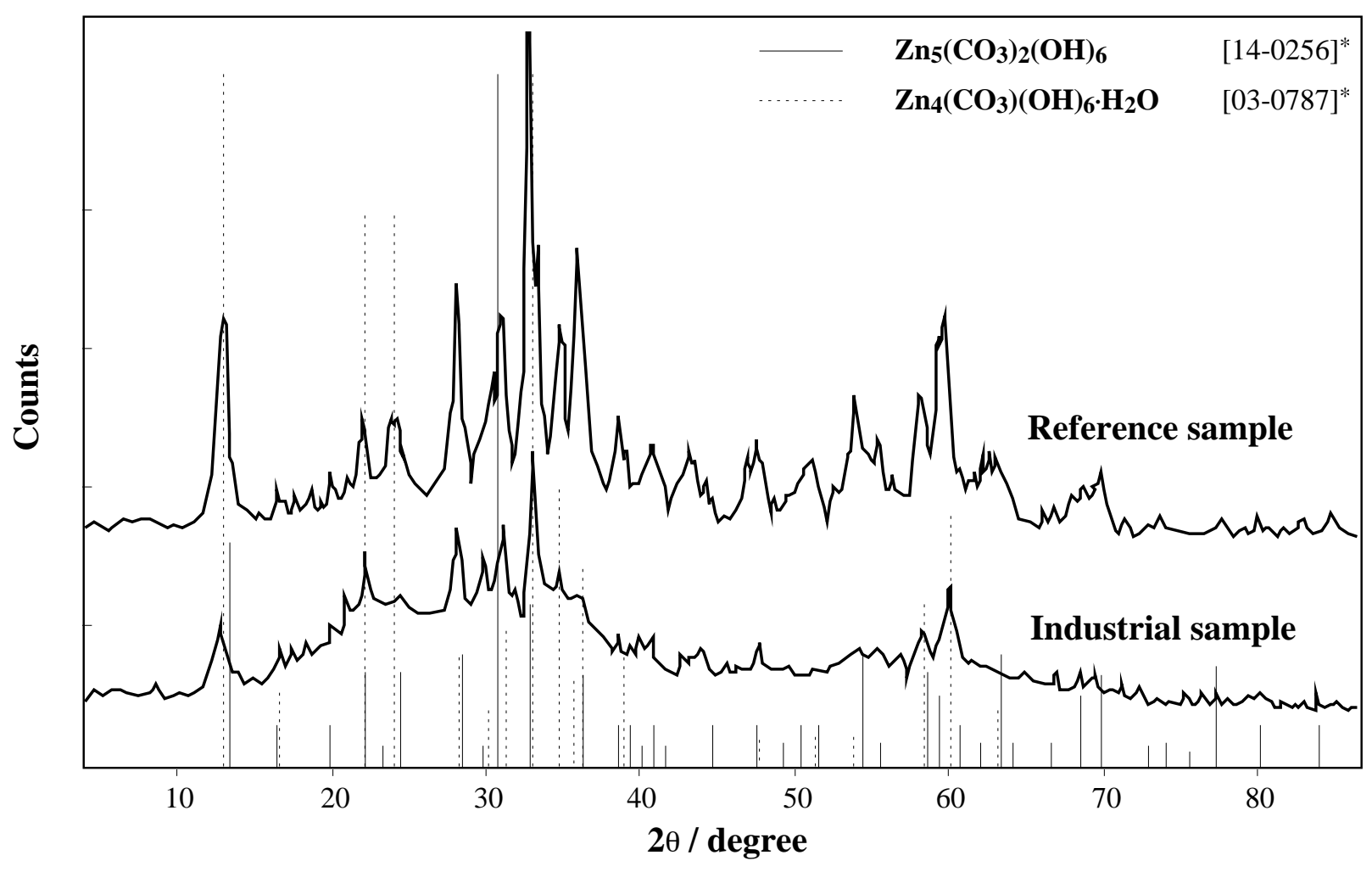

Fig. 1 : XRD results of zinc carbonate hydroxide samples.
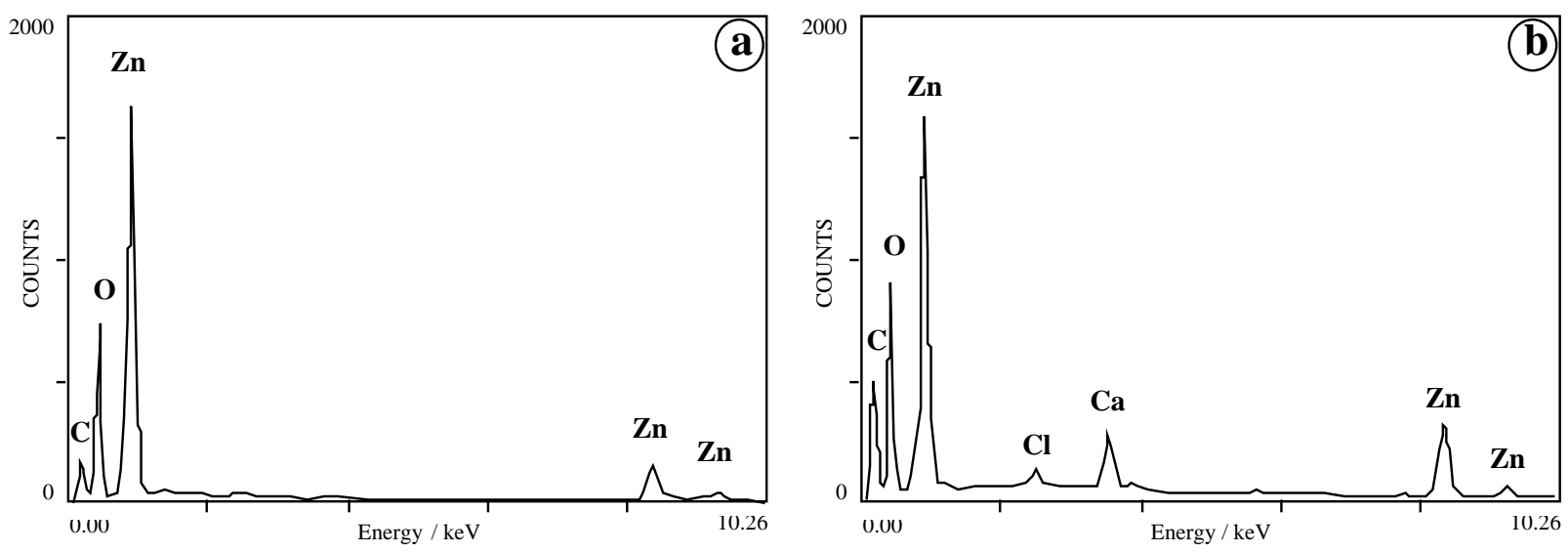

Fig. 2: SEM-EDS spectra of the zinc carbonate hydroxide samples

(a) : Reference sample,

(b) : Industrial sample. 


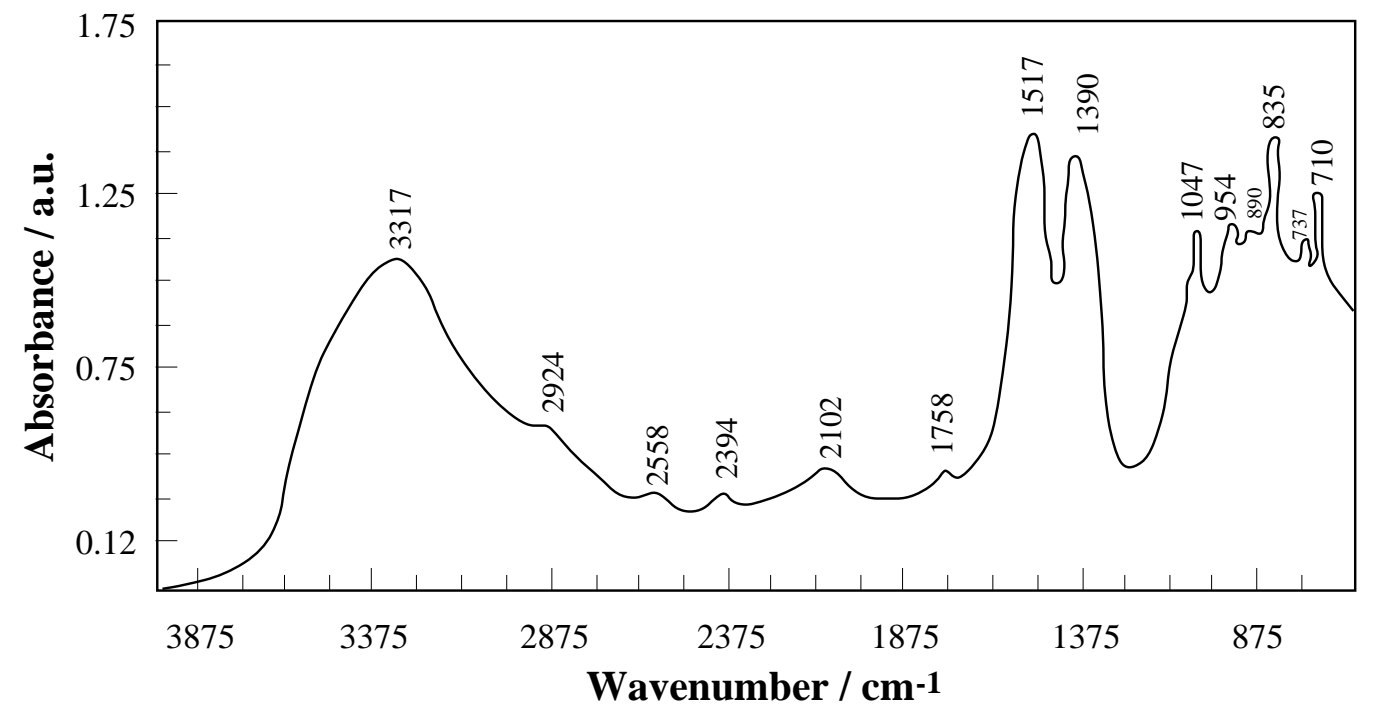

Fig. 3 : FTIR of the reference sample.

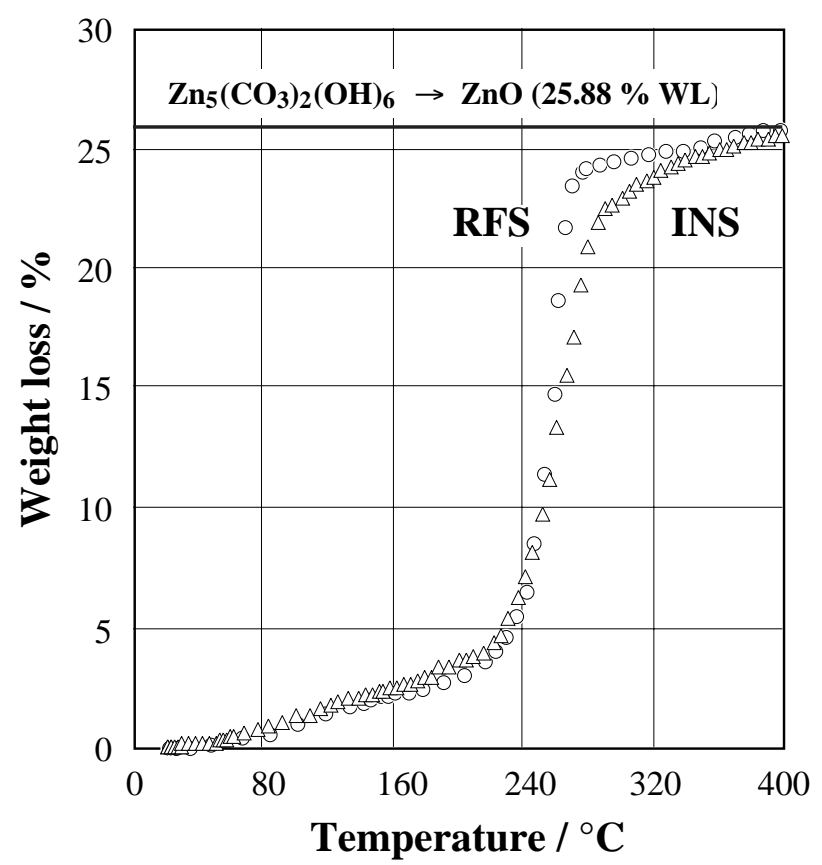

Fig. 4 : TG non isothermal treatment of samples.

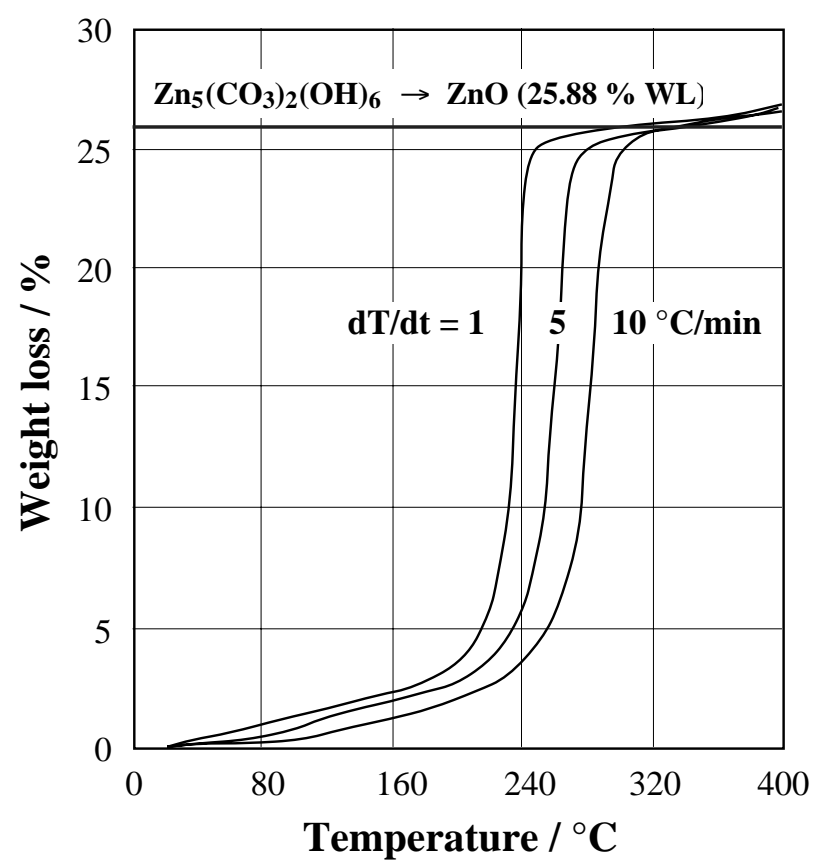

Fig. 5 : Treatment of RFS at different heating rates. 

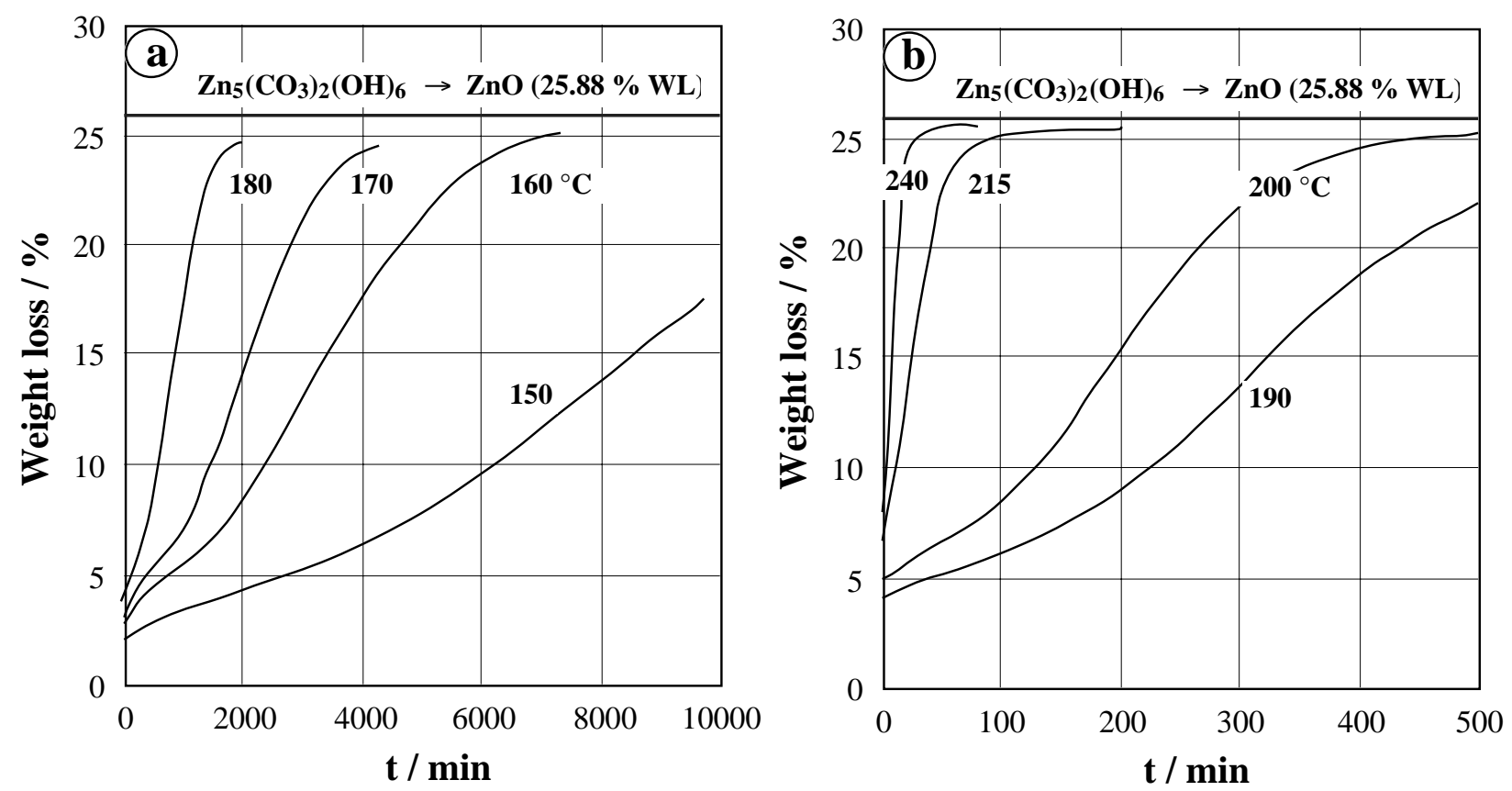

Fig. 6 : Isothermal treatment of RFS between 150 and $240{ }^{\circ} \mathrm{C}$.
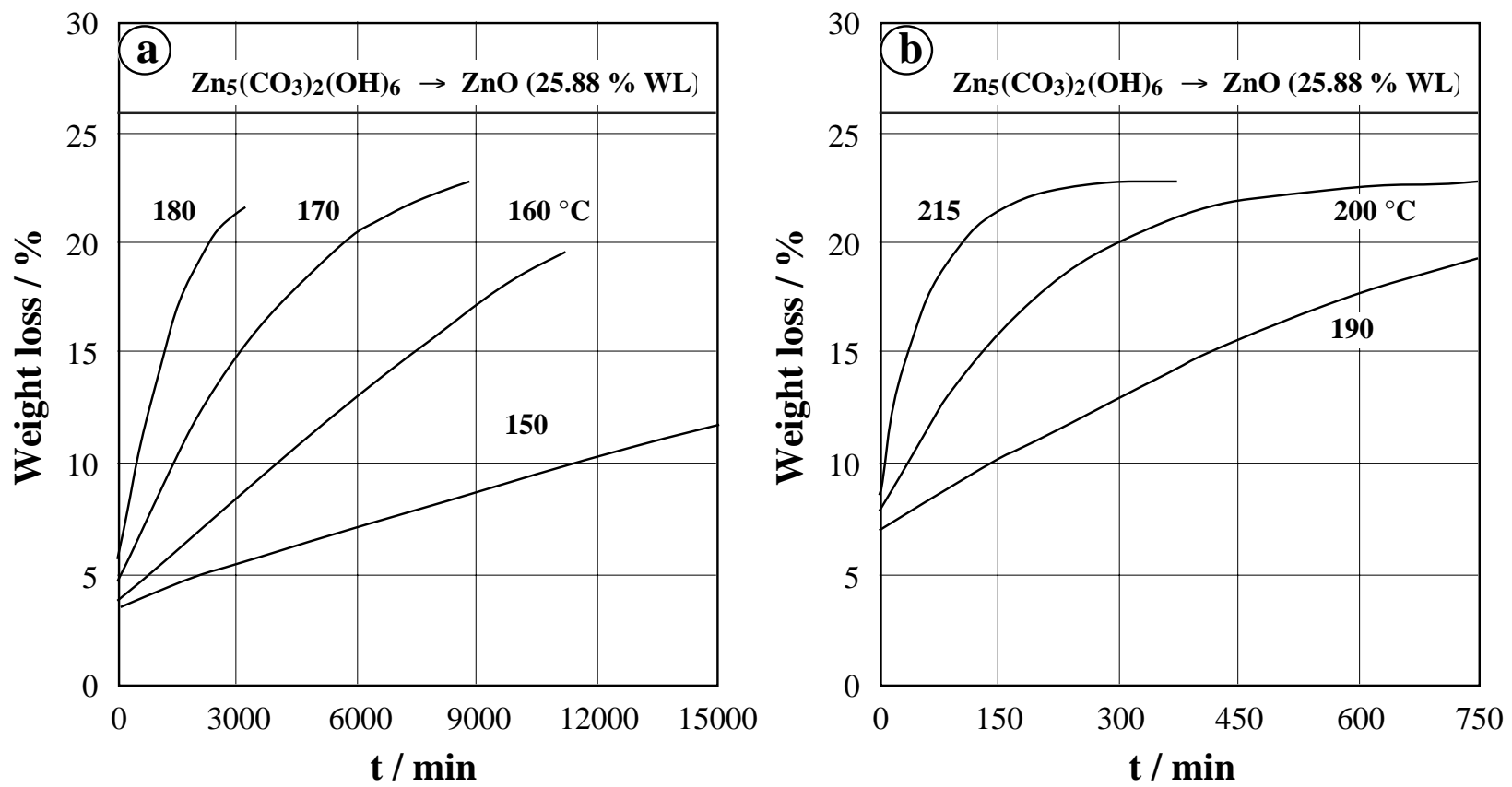

Fig. 7 : Isothermal treatment of INS between 150 and $215^{\circ} \mathrm{C}$. 


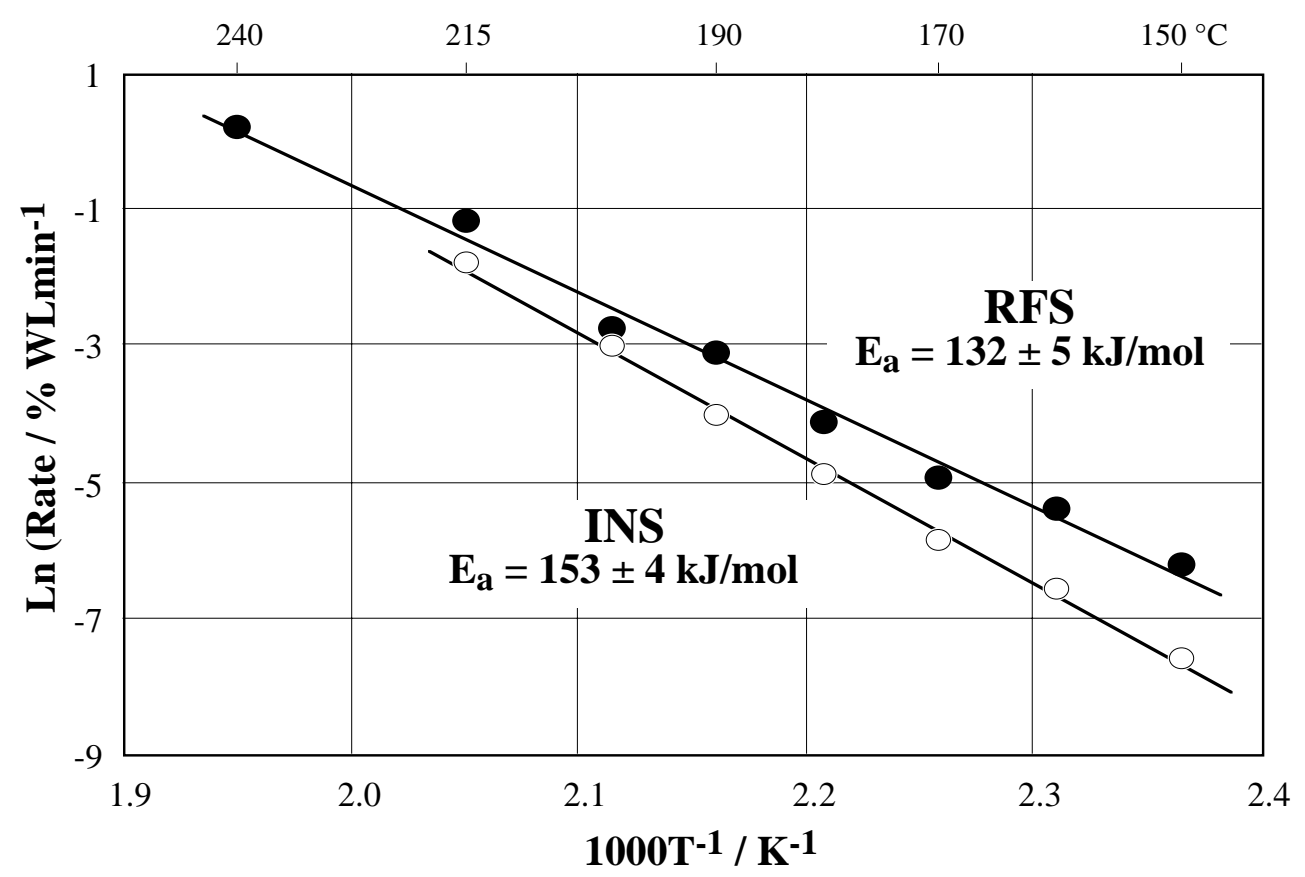

Fig. 8 : Arrhenius diagrams of decomposition of both samples.

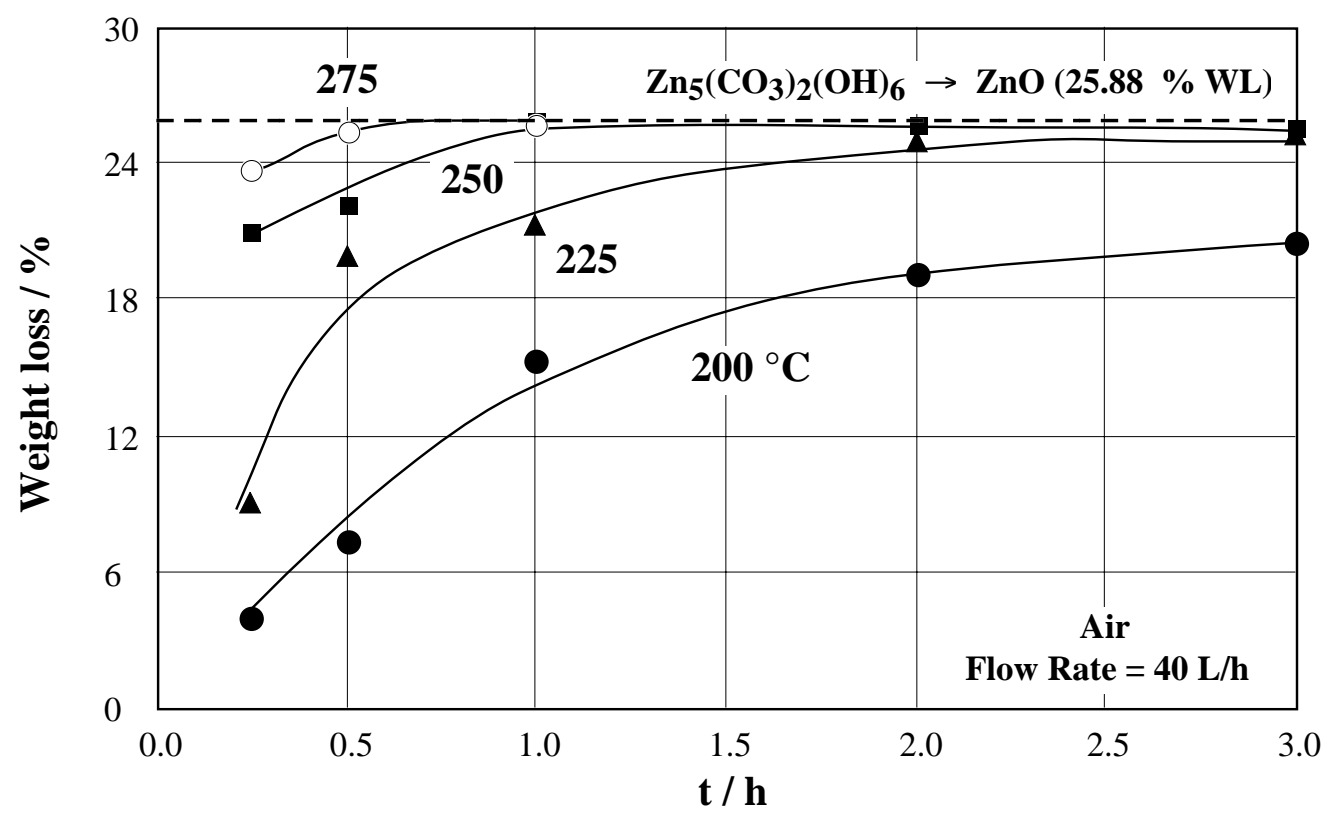

Fig. 9 : Treatment of RFS between 200 and $275^{\circ} \mathrm{C}$ at different times. 


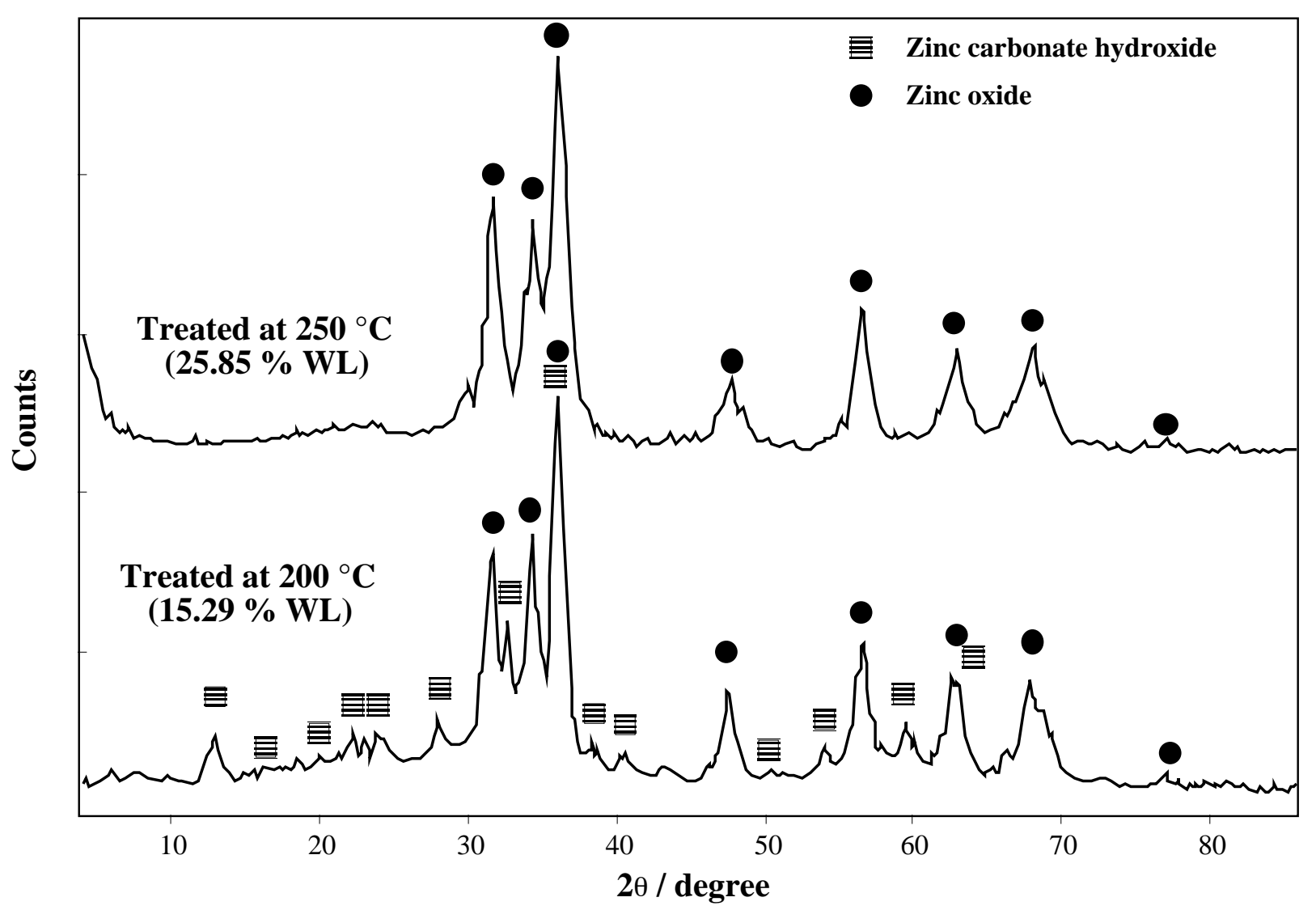

Fig. 10 : XRD result of RFS treated at 200 and $250{ }^{\circ} \mathrm{C}$.

Temperature $/{ }^{\circ} \mathrm{C}$

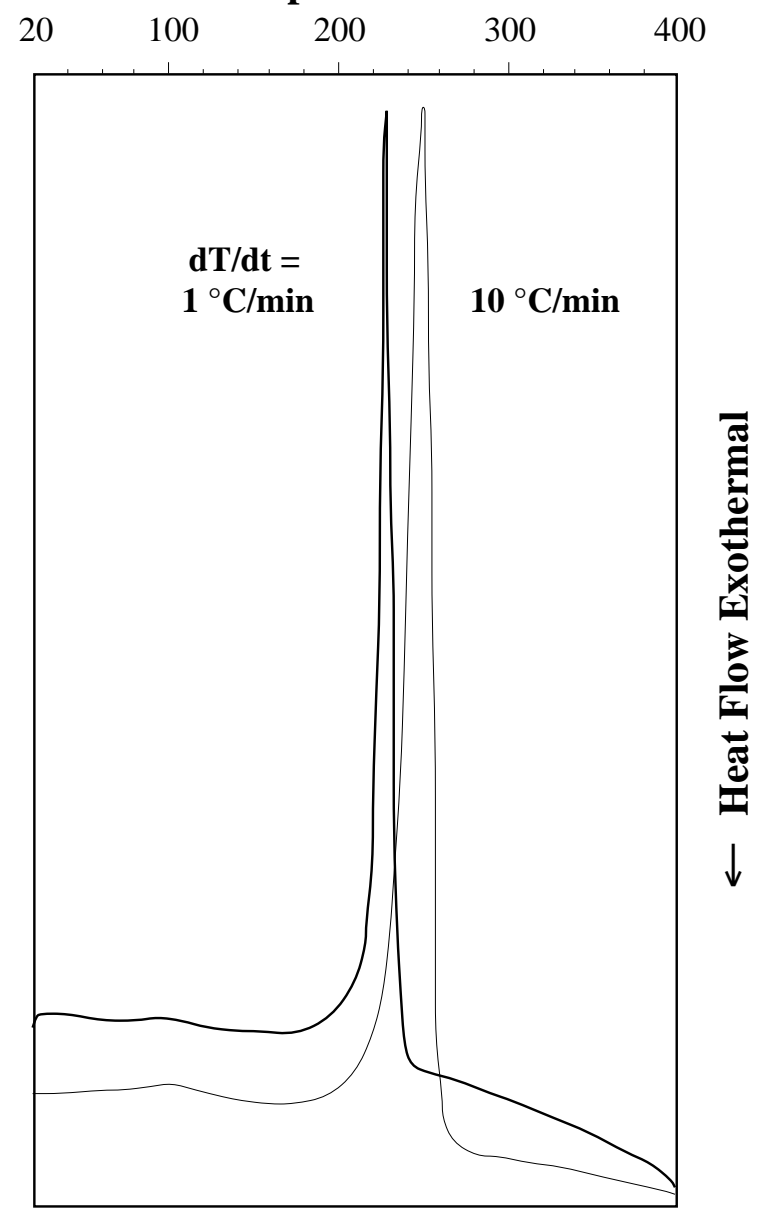

Fig. 11 : DSC results of the reference sample. 


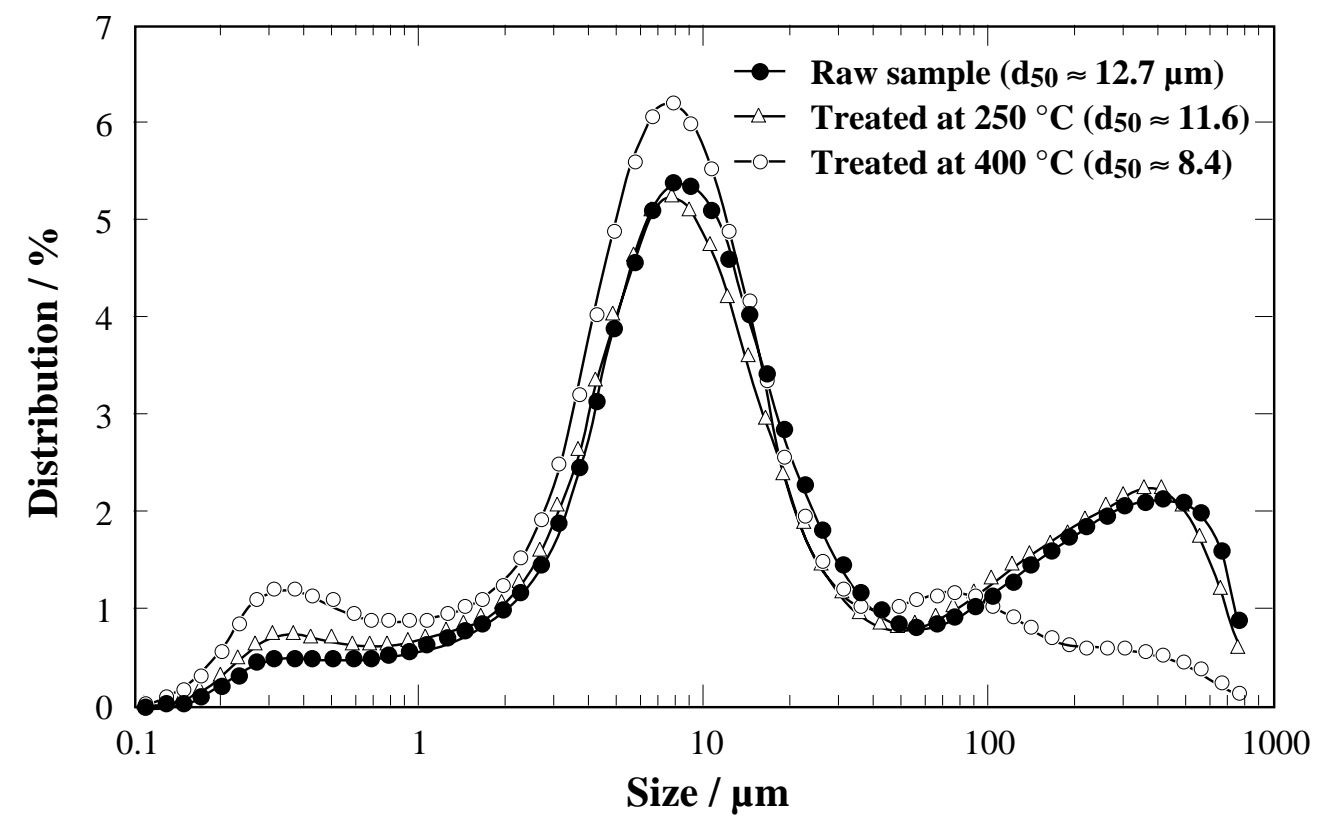

Fig. 12 : Evolution of the particle sizes during the treatment of RFS at 250 and $400{ }^{\circ} \mathrm{C}$.
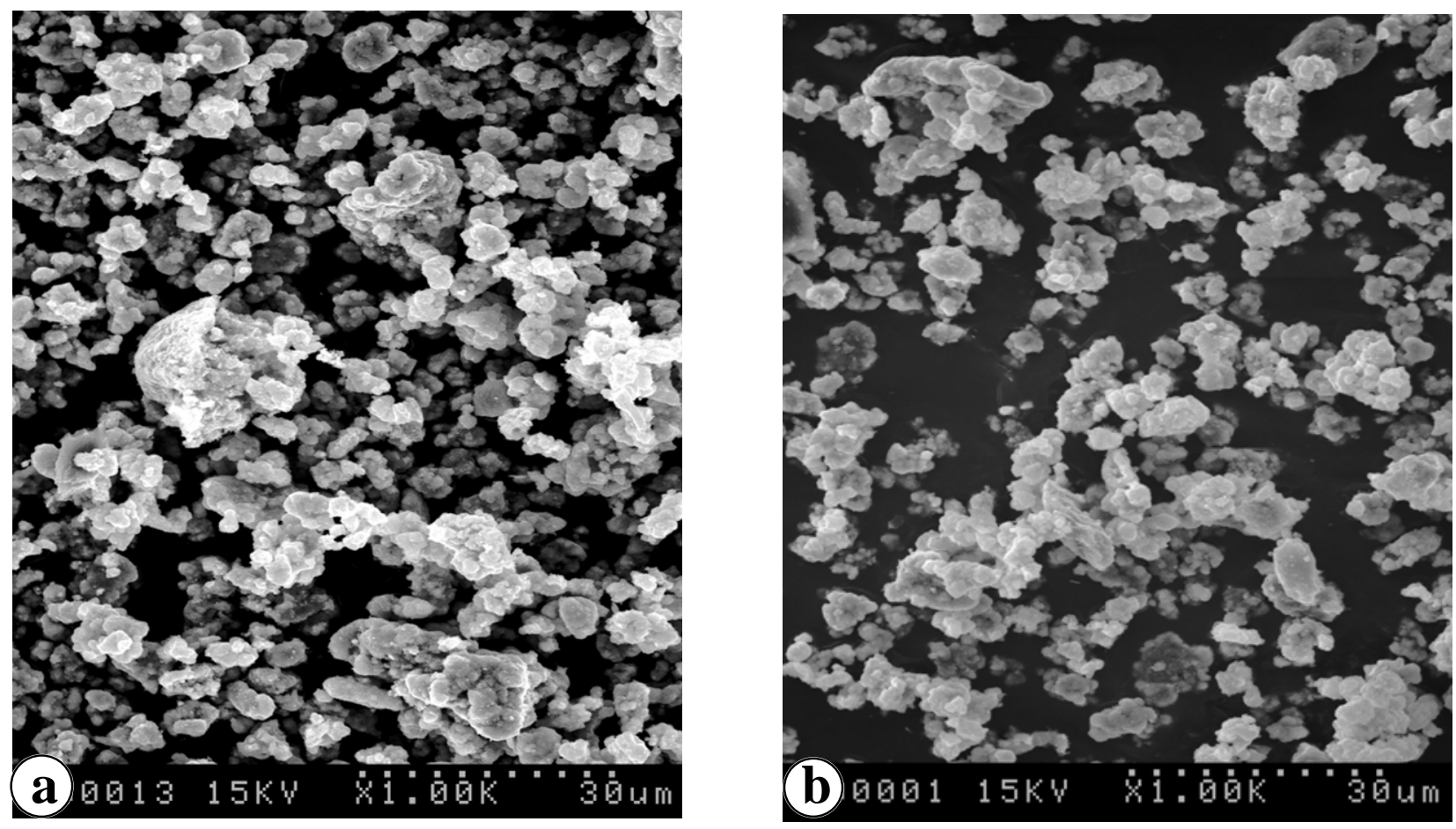

Fig. 13 : SEM micrograph of the reference sample

(a) : Non treated,

(b) : Decomposed at $250{ }^{\circ} \mathrm{C}$.. 